\title{
An empirical evaluation of the adequacy of self- assessed knowledge competency in a certified population of women's health care nurse practitioners
}

\author{
Fran H. Byrd, Betty Burns, Barbara L. Grossklags \\ National Certification Corporation, Chicago, USA \\ Correspondence: Fran H. Byrd. Address: 142 E. Ontario, Suite 1700, Chicago, IL 60611, USA. Email: fbyrd@nccnet.org. \\ Received: July 1, 2012 \\ Accepted: August 16, $2012 \quad$ Online Published: December 26, 2012 \\ DOI : 10.5430/jnep.v3n6p11 \\ URL: http://dx.doi.org/10.5430/jnep.v3n6p11
}

\begin{abstract}
Background: From a multitude of recognized sources which include the PEW Commission, the Institute of Medicine, and the Citizen Advocacy Center as well as from healthcare consumers in general, there has been a persistent call for change in the processes used to demonstrate ongoing competency of health care professionals after initial licensure or certification in their specialty. In response to such long-standing demands for accountability, the Board of Directors of the National Certification Corporation (NCC), a nationally accredited, not-for-profit voluntary certification organization, approved development of a pilot project to address these concerns. The pilot project's major objective was to determine if NCCcertified nurses could appropriately self-assess their areas of strength and weakness related to the knowledge competencies for the active certification examination in their specialty. And further, to determine if the accuracy of their self-assessment of competency varied across subgroups for that specialty.
\end{abstract}

Methods: Study participants were selected in three separate random samples from NCC-certified Women's Health Care Nurse Practitioners (WHNP). Common criteria used across all three sample groups included a certification maintenance cycle of 2009, stratification of the number of years of specialty experience based on NCC maintenance cycles and geographic distribution. The final sample sizes were 487, 485 and 476. Participants across all sample groups completed a survey instrument developed to obtain each individual's self-assessment of their knowledge competency in Gynecology, Obstetrics and Primary Care as subgroups covered in their core certification examination. Once the survey tool was completed, one of three forms of a 100 item test instrument was administered. Content in each of the forms was distributed as $50 \%$ gynecology, $30 \%$ obstetrics and $20 \%$ primary care. Sample One received a form in which all items represented entry into practice level; Sample Two was presented with items that reflected new information in the specialty field and Sample Three completed a form comprised of a combination of basic and new information.

Results: The Pearson product moment correlation coefficients were calculated among the three separate self-assessed competency ratings and the four test scores (total, gynecology, obstetrics and primary care). Psychometric consideration of the results as a whole raised concerns about the substantive interpretation of correlation coefficient as an effect size and led to summary findings that did not support self-ratings as an accurate method of knowledge assessment in this population. A mechanism to directly examine knowledge competencies was recommended. In regard to the question of constituent 
accuracy of assessment across specialty subgroups, participants across all samples were found to be more accurate in self-assessing their weaknesses in gynecology and obstetrics than they were in primary care.

Conclusions: Based on the overall findings of the pilot project, the NCC Board of Directors approved development of a Continuing Competency Initiative to transition certification maintenance from a constituent-assessed and selected continuing education process to a new format. As recommended by the study findings, the new Professional Development Maintenance Program is based on a third party administered evaluation tool to provide individualized direction for certification maintenance.

\section{Key words}

Continuing competency, Self-assessment, Life-long learning, Certified nurses

\section{Introduction}

Since the early 1990's, a number of organizations and agencies have produced public policy initiatives and reports with recommendations in regard to ongoing assessment and maintenance of competency in health care professionals ${ }^{[1-5]}$. The summary findings of the 1995 PEW Commission report Reforming Health Care Workforce Regulation called for mechanisms to address both initial and ongoing competency assessments for health care professionals ${ }^{[5]}$. A major recommendation of the Institute of Medicine's Health Professions Education -A Bridge to Quality emphasized the need to have regulators ensure continuing competency of health care professionals throughout their active professional career ${ }^{[2]}$. The Citizen Advocacy Center's five-step CAC Road Map released in April 2004 was developed over a period of several years and involved a host of stakeholders. This document sought to identify and address problems that inhibit the implementation of continuing competency assessment throughout the health care professions ${ }^{[3]}$. CAC has continued to follow developments in the realm of continuing competency initiatives related to health care professionals and to make recommendations to the various stakeholders involved in the process ${ }^{[6]}$. The Institute of Medicine's report To Err is Human: Building a Safer Health System identified and highlighted the magnitude of preventable medical errors and the resultant impact on overall quality of care and patient safety ${ }^{[7]}$. Health care consumer demands for action were added to the long list of stakeholders that included state boards, federal agencies and independent entities including the Joint Commission through its evaluation of health care organizations ${ }^{[8]}$.

The Board of Directors of the National Certification Corporation (NCC), a nationally accredited, not-for-profit voluntary certification organization, recognized their role in these quality and patient-safety driven initiatives and focused attention on the existing NCC certification maintenance program. The specific objective was to evaluate the existing maintenance program's ability to validate continuing competency in the NCC-certified population. The cornerstone of the maintenance process at that time was continuing education accrued on the basis of the constituent's self-assessment of their specialty needs. In 2005, the NCC Board of Directors approved development of a pilot project to determine if self-assessment of knowledge competency needs related to an individual's NCC specialty area was accurate and appropriate as the basis for continuing education activities used to support ongoing maintenance of their NCC credential.

The pilot project was designed to answer the following specific questions:

1) How accurately do NCC-certified WHNP constituents self-assess knowledge competency related to their specialty?

2) Does the accuracy of self-assessment vary across the clinical subgroups (Gynecology, Obstetrics and Primary Care) of the WHNP specialty? 


\section{Subjects and methods}

An original randomly selected group of 1500 NCC-certified Women's Health Care Nurse Practitioners was offered the opportunity to participate in the pilot project in lieu of standard maintenance requirements and fees for their 2009 maintenance cycle. A total of 52 individuals were excluded from the final study group selection process as they either declined to participate in the voluntary pilot project or failed to complete the survey or testing instrument. The final study group was comprised of three random sample sizes of 487, 485 and 476 (total 1448) with the following criteria applied across all samples:

1) Scheduled to maintain NCC certification status in 2009

2) Years in practice stratified by original year of NCC certification
a) New - 2000, 2003, 2006
b) Middle - 1994, 1997
c) Long-term - 1981, 1982, 1985

3) Geographic distribution

Additional baseline professional demographics as reflected in Table 1(Sample Group Professional Demographics) were collected at the same time the initial survey tool was completed. Although this information was not specific to the primary objectives of the pilot project, similarities in practice experience, level of education and percent of time spent in clinical subgroups of the specialty are notable across the three sample groups.

Table 1. Sample Group Professional Demographics

\begin{tabular}{|c|c|c|c|}
\hline Item & Sample 1 ( \# 487) & Sample 2 (\#485) & Sample 3 (\#476) \\
\hline \multicolumn{4}{|c|}{ Years of Practice Experience by \% of Sample Group } \\
\hline 17 or more yrs & 33.7 & 32.6 & 33.6 \\
\hline $9-16$ yrs & 33.5 & 33.8 & 33.0 \\
\hline 8 or less yrs & 32.8 & 33.6 & 33.4 \\
\hline \multicolumn{4}{|c|}{ Level of Professional Education by \% of Sample Group } \\
\hline Certificate & 51.1 & 50.1 & 0.2 \\
\hline Master's & 46.0 & 45.2 & 50.8 \\
\hline Post Master's & 2.9 & 4.7 & 45.0 \\
\hline Absent/bad data & & & 4.0 \\
\hline \multicolumn{4}{|c|}{ \% of Practice Time by Clinical Subgroup As Reported by } \\
\hline \multicolumn{4}{|l|}{ Sample Group } \\
\hline Majority in Primary Care & 8.8 & 7.0 & 7.0 \\
\hline Majority in Gynecology & 42.9 & 38.3 & 38.3 \\
\hline Majority in Obstetrics & 13.4 & 12.2 & 12.2 \\
\hline Equal Gyn/OB & 15.2 & 18.8 & 18.8 \\
\hline Equal all 3 areas & 1.2 & 2.1 & 2.1 \\
\hline Not employed in WH & 5.3 & 5.5 & 5.5 \\
\hline Not currently employed & 10.5 & 2.5 & 2.5 \\
\hline Absent or bad data & 2.7 & 13.6 & 13.6 \\
\hline
\end{tabular}

A survey instrument composed of a rating scale for WHNP constituents to self-report their personal level of knowledge competency related to the Gynecology, Obstetric and Primary Care clinical subgroups of the WHNP certification specialty was developed. Figure 1 contains the survey items and rating scale used to obtain the self-ratings in the WHNP specialty subgroups (Self-Assessed Competency Survey Items for WHNP Clinical Subgroups). 
Where do you rate your knowledge competency in Primary Care (includes health assessment and pharmacology)
A. Expert
B. Proficient
C. Average
D. Below Average
E. Weak

Where do you rate your knowledge competency in Gynecology (includes health assessment and pharmacology)
A. Expert
B. Proficient
C. Average
D. Below Average
E. Weak

Where do you rate your knowledge competency in Obstetrics (includes health assessment and pharmacology)
A. Expert
B. Proficient
C. Average
D. Below Average
E. Weak

Figure 1. Self-Assessed Competency Survey Items for WHNP Clinical Subgroups

Once the completed knowledge competency self-assessment tool was obtained from each sample group participant, a 100 item test was administered to each candidate. The content of the testing instrument was reflective of the distribution of the clinical subgroup content on the active core WHNP certification examination. Overall item distribution was 50 items with gynecology focus, 30 items with a focus on obstetrics and 20 items that addressed primary care content. (Since the content of the 100 item testing instrument was similar in nature to secure WHNP core examination items, the testing instrument itself is not included in the content of this article.)

Three forms of the test were created for use in the evaluation process. Sample One participants received a form in which all items were comprised of content at the entry into practice level. Participants in Sample Two received a form whose items were developed from recent research or practice findings in the specialty field and Sample Three participants were administered a form with a combination of entry level and new research/practice items.

Pearson product moment correlation coefficients were calculated as a method of answering the questions posed. The coefficients were calculated among the three self-assessed competency ratings and the four test scores (total and gynecology, obstetrics and primary care subgroups). A higher level of agreement between the self-assessment ratings of the WHNP participants and their test scores is indicated by higher correlation coefficients.

Table 2 reflects the descriptive statistics and calculated correlations for Sample One, Form 1 that was composed of entry into practice level items designed to test basic knowledge competency in the specialty. There were 487 WHNP constituents who completed Form 1. Correlations ranged from .297 to .462 among the three self-assessment ratings. The correlations among the four test scores were higher ranging from .466 to .867. The range for the accuracy correlations was .058 to .351 . Of note, the Primary Care self-assessment rating did not have statistically significant correlations with any of the test scores. The WHNP constituents were able to rate their knowledge competency within Gynecology $(r=.221, p<.01)$ and Obstetrics $(r=.351, p=<.01)$. Table 2 is Sample One which contains table 2-1 and table 2-2. 
Table 2-1. Descriptive Statistics

\begin{tabular}{llll}
\hline & Mean & Std. Deviation & N \\
\hline SAC_PC & 3.0185 & .67408 & 487 \\
SAC_GYN & 3.7372 & .74309 & 487 \\
SAC_OB & 3.3778 & .93015 & 487 \\
TOTAL & 64.65 & 9.764 & 487 \\
PC & 12.60 & 2.461 & 487 \\
GYN & 31.75 & 5.081 & 487 \\
OB & 20.29 & 4.365 & 487 \\
\hline
\end{tabular}

SAC = Self assessed competency; PC = Primary Care; GYN = Gynecology; OB = Obstetrics

Table 2-2. Correlations

\begin{tabular}{|c|c|c|c|c|c|c|c|c|}
\hline & & SAC_PC & SAC_GYN & SAC_OB & TOTAL & PC & GYN & OB \\
\hline \multirow[t]{3}{*}{ SAC_PC } & Pearson Correlation & 1 & $.462(* *)$ & $.297(* *)$ & .082 & .085 & .067 & .058 \\
\hline & Sig. (2-tailed) & & .000 & .000 & .071 & .061 & .141 & .205 \\
\hline & $\mathrm{N}$ & 487 & 487 & 487 & 487 & 487 & 487 & 487 \\
\hline \multirow[t]{3}{*}{ SAC_GYN } & Pearson Correlation & $.462(* *)$ & 1 & $.361(* *)$ & $.208(* *)$ & $.148(* *)$ & $.221(* *)$ & $.125(* *)$ \\
\hline & Sig. (2-tailed) & .000 & & .000 & .000 & .001 & .000 & .006 \\
\hline & $\mathrm{N}$ & 487 & 487 & 487 & 487 & 487 & 487 & 487 \\
\hline \multirow[t]{3}{*}{ SAC_OB } & Pearson Correlation & $.297(* *)$ & $.361(* *)$ & 1 & $.252(* *)$ & $.148(* *)$ & $.111(*)$ & $.351(* *)$ \\
\hline & Sig. (2-tailed) & .000 & .000 & & .000 & .001 & .014 & .000 \\
\hline & $\mathrm{N}$ & 487 & 487 & 487 & 487 & 487 & 487 & 487 \\
\hline \multirow[t]{3}{*}{ TOTAL } & Pearson Correlation & .082 & $.208(* *)$ & $.252(* *)$ & 1 & $.743(* *)$ & $.867(* *)$ & $.809(* *)$ \\
\hline & Sig. (2-tailed) & .071 & .000 & .000 & & .000 & .000 & .000 \\
\hline & $\mathrm{N}$ & 487 & 487 & 487 & 487 & 487 & 487 & 487 \\
\hline \multirow[t]{3}{*}{ PC } & Pearson Correlation & .085 & $.148(* *)$ & $.148(* *)$ & $.743(* *)$ & 1 & $.544(* *)$ & $.466(* *)$ \\
\hline & Sig. (2-tailed) & .061 & .001 & .001 & .000 & & .000 & .000 \\
\hline & $\mathrm{N}$ & 487 & 487 & 487 & 487 & 487 & 487 & 487 \\
\hline \multirow[t]{3}{*}{ GYN } & Pearson Correlation & .067 & $.221(* *)$ & $.111(*)$ & $.867(* *)$ & $.544(* *)$ & 1 & $.469(* *)$ \\
\hline & Sig. (2-tailed) & .141 & .000 & .014 & .000 & .000 & & .000 \\
\hline & $\mathrm{N}$ & 487 & 487 & 487 & 487 & 487 & 487 & 487 \\
\hline \multirow[t]{3}{*}{ OB } & Pearson Correlation & .058 & $.125(* *)$ & $.351(* *)$ & $.809(* *)$ & $.466(* *)$ & $.469(* *)$ & 1 \\
\hline & Sig. (2-tailed) & .205 & .006 & .000 & .000 & .000 & .000 & \\
\hline & $\mathrm{N}$ & 487 & 487 & 487 & 487 & 487 & 487 & 487 \\
\hline
\end{tabular}

** Correlation is significant at the 0.01 level (2-tailed).* Correlation is significant at the 0.05 level (2-tailed).

Table 3 reflects the descriptive statistics and calculated correlations for Sample Two, Form 2 that used new research and practice items designed to test new knowledge competency in the specialty. There were 485 WHNP constituents who completed Form 2. Correlations ranged from .296 to .445 among the three self-assessment ratings. The correlations among the four test scores were higher ranging from .240 to .835 . The range for the accuracy correlations was .015 to .325 . The Primary Care self-assessment rating had the smallest accuracy correlation with any of the test scores. The WHNP constituents were able to rate their knowledge competency within Gynecology $(r=.317, p<.01)$ and Obstetrics $(r=.325$, $p=<.01$ ). Table 3 is Sample Two which contains table 3-1 and table 3-2. 
Table 3-1. Descriptive Statistics

\begin{tabular}{llll}
\hline & Mean & Std. Deviation & N \\
\hline SAC_PC & 2.95 & .725 & 484 \\
SAC_GYN & 3.61 & .771 & 485 \\
SAC_OB & 3.29 & .915 & 485 \\
TOTAL & 55.35 & 8.314 & 485 \\
PC & 11.94 & 2.273 & 485 \\
GYN & 28.66 & 4.758 & 485 \\
OB & 14.39 & 3.886 & 485 \\
\hline
\end{tabular}

SAC = Self assessed competency; PC = Primary Care; GYN = Gynecology; OB = Obstetrics

Table 3-2. Correlations

\begin{tabular}{|c|c|c|c|c|c|c|c|c|}
\hline & & SAC_PC & SAC_GYN & SAC_OB & TOTAL & PC & GYN & OB \\
\hline \multirow[t]{3}{*}{ SAC_PC } & Pearson Correlation & 1 & $.419(* *)$ & $.296(* *)$ & $.122(* *)$ & $.102(*)$ & $.141(* *)$ & .015 \\
\hline & Sig. (2-tailed) & & .000 & .000 & .007 & .024 & .002 & .747 \\
\hline & $\mathrm{N}$ & 484 & 484 & 484 & 484 & 484 & 484 & 484 \\
\hline \multirow[t]{3}{*}{ SAC_GYN } & Pearson Correlation & $.419(* *)$ & 1 & $.445(* *)$ & $.304(* *)$ & $.158(* *)$ & $.317(* *)$ & $.146(* *)$ \\
\hline & Sig. (2-tailed) & .000 & & .000 & .000 & .000 & .000 & .001 \\
\hline & $\mathrm{N}$ & 484 & 485 & 485 & 485 & 485 & 485 & 485 \\
\hline \multirow[t]{3}{*}{ SAC_OB } & Pearson Correlation & $.296(* *)$ & $.445(* *)$ & 1 & $.204(* *)$ & -.004 & .086 & $.325(* *)$ \\
\hline & Sig. (2-tailed) & .000 & .000 & & .000 & .923 & .059 & .000 \\
\hline & $\mathrm{N}$ & 484 & 485 & 485 & 485 & 485 & 485 & 485 \\
\hline \multirow[t]{3}{*}{ TOTAL } & Pearson Correlation & $.122(* *)$ & $.304(* *)$ & $.204(* *)$ & 1 & $.621(* *)$ & $.835(* *)$ & $.719(* *)$ \\
\hline & Sig. (2-tailed) & .007 & .000 & .000 & & .000 & .000 & .000 \\
\hline & $\mathrm{N}$ & 484 & 485 & 485 & 485 & 485 & 485 & 485 \\
\hline \multirow[t]{3}{*}{ PC } & Pearson Correlation & $.102\left(^{*}\right)$ & $.158(* *)$ & -.004 & $.621(* *)$ & 1 & $.392(* *)$ & $.240(* *)$ \\
\hline & Sig. (2-tailed) & .024 & .000 & .923 & .000 & & .000 & .000 \\
\hline & $\mathrm{N}$ & 484 & 485 & 485 & 485 & 485 & 485 & 485 \\
\hline \multirow[t]{3}{*}{ GYN } & Pearson Correlation & $.141(* *)$ & $.317(* *)$ & .086 & $.835(* *)$ & $.392(* *)$ & 1 & $.310(* *)$ \\
\hline & Sig. (2-tailed) & .002 & .000 & .059 & .000 & .000 & & .000 \\
\hline & $\mathrm{N}$ & 484 & 485 & 485 & 485 & 485 & 485 & 485 \\
\hline \multirow[t]{3}{*}{ OB } & Pearson Correlation & .015 & $.146(* *)$ & $.325(* *)$ & $.719(* *)$ & $.240(* *)$ & $.310(* *)$ & 1 \\
\hline & Sig. (2-tailed) & .747 & .001 & .000 & .000 & .000 & .000 & \\
\hline & $\mathrm{N}$ & 484 & 485 & 485 & 485 & 485 & 485 & 485 \\
\hline
\end{tabular}

** Correlation is significant at the 0.01 level (2-tailed).* Correlation is significant at the 0.05 level (2-tailed).

Table 4 reflects the descriptive statistics and calculated correlations for Sample Three, Form 3 comprised of a combination of items that represented both entry into practice level and new research and practice findings in the specialty. There were 476 WHNP constituents who completed Form 3. Correlations ranged from .330 to .441 among the three self-assessment ratings. The correlations among the four test scores were higher ranging from .280 to .799. The range for the accuracy correlations was -.051 to .283. The Primary Care self-assessment rating had the smallest accuracy correlation of any of the test scores. The WHNP constituents were able to rate their knowledge competency within Gynecology $(r=.283, p<.01)$ and Obstetrics $(r=.160, p=<.01)$. Table 4 is Sample Three which contains table 4-1 and table 4-2. 
Table 4-1. Descriptive Statistics

\begin{tabular}{llll}
\hline & Mean & Std. Deviation & N \\
\hline SAC_PC & 3.06 & .717 & 476 \\
SAC_GYN & 3.67 & .747 & 476 \\
SAC_OB & 3.35 & .902 & 476 \\
TOTAL & 59.29 & 7.625 & 476 \\
PC & 14.21 & 2.133 & 476 \\
GYN & 28.46 & 4.313 & 476 \\
OB & 16.62 & 3.789 & 476 \\
\hline
\end{tabular}

SAC = Self assessed competency; $\mathrm{PC}=$ Primary Care; $\mathrm{GYN}=$ Gynecology; $\mathrm{OB}=$ Obstetrics

Table 4-2. Correlations

\begin{tabular}{|c|c|c|c|c|c|c|c|c|}
\hline & & SAC_PC & SAC_GYN & SAC_OB & TOTAL & PC & GYN & OB \\
\hline \multirow[t]{3}{*}{ SAC_PC } & Pearson Correlation & 1 & $.441(* *)$ & $.330(* *)$ & $.115(*)$ & $.135(* *)$ & .071 & .076 \\
\hline & Sig. (2-tailed) & & .000 & .000 & .012 & .003 & .123 & .099 \\
\hline & $\mathrm{N}$ & 476 & 476 & 476 & 476 & 476 & 476 & 476 \\
\hline \multirow[t]{3}{*}{ SAC_GYN } & Pearson Correlation & $.441(* *)$ & 1 & $.409(* *)$ & $.232(* *)$ & $.119(* *)$ & $.283(* *)$ & .078 \\
\hline & Sig. (2-tailed) & .000 & & .000 & .000 & .009 & .000 & .090 \\
\hline & $\mathrm{N}$ & 476 & 476 & 476 & 476 & 476 & 476 & 476 \\
\hline \multirow[t]{3}{*}{ SAC_OB } & Pearson Correlation & $.330(* *)$ & $.409(* *)$ & 1 & .070 & -.051 & .008 & $.160(* *)$ \\
\hline & Sig. (2-tailed) & .000 & .000 & & .130 & .264 & .866 & .000 \\
\hline & $\mathrm{N}$ & 476 & 476 & 476 & 476 & 476 & 476 & 476 \\
\hline \multirow[t]{3}{*}{ TOTAL } & Pearson Correlation & $.115(*)$ & $.232(* *)$ & .070 & 1 & $.632(* *)$ & $.799(* *)$ & $.747(* *)$ \\
\hline & Sig. (2-tailed) & .012 & .000 & .130 & & .000 & .000 & .000 \\
\hline & $\mathrm{N}$ & 476 & 476 & 476 & 476 & 476 & 476 & 476 \\
\hline \multirow[t]{3}{*}{ PC } & Pearson Correlation & $.135(* *)$ & $.119(* *)$ & -.051 & $.632(* *)$ & 1 & $.337(* *)$ & $.326(* *)$ \\
\hline & Sig. (2-tailed) & .003 & .009 & .264 & .000 & & .000 & .000 \\
\hline & $\mathrm{N}$ & 476 & 476 & 476 & 476 & 476 & 476 & 476 \\
\hline \multirow[t]{3}{*}{ GYN } & Pearson Correlation & .071 & $.283(* *)$ & .008 & $.799(* *)$ & $.337(* *)$ & 1 & $.280(* *)$ \\
\hline & Sig. (2-tailed) & .123 & .000 & .866 & .000 & .000 & & .000 \\
\hline & $\mathrm{N}$ & 476 & 476 & 476 & 476 & 476 & 476 & 476 \\
\hline \multirow[t]{3}{*}{ OB } & Pearson Correlation & .076 & .078 & $.160(* *)$ & $.747(* *)$ & $.326(* *)$ & $.280(* *)$ & 1 \\
\hline & Sig. (2-tailed) & .099 & .090 & .000 & .000 & .000 & .000 & \\
\hline & $\mathrm{N}$ & 476 & 476 & 476 & 476 & 476 & 476 & 476 \\
\hline
\end{tabular}

** Correlation is significant at the 0.01 level (2-tailed).* Correlation is significant at the 0.05 level (2-tailed).

\section{Results}

The primary question and underlying basis for the study was to determine if a population of certified nurses, represented in this study by Women's Health Care Nurse Practitioners, could accurately self-assess knowledge competency aligned with their certification specialty. The NCC Women's Health Care Nurse Practitioner certification examination is used by many states as a regulatory mechanism for validation of readiness for entry into practice. Included in the WHNP certification examination are defined knowledge competencies and core content categories that reflect the role of the WHNP in the clinical areas of gynecology, obstetrics and primary care. Although statistical significance at the 0.01 and 0.05 level was 
observed for correlation coefficients as presented in Tables 2, 3 and 4, the ability to use these findings as an accurate prediction of knowledge competency was considered to be questionable based on the substantive interpretation of correlation coefficient as an effect size. For example, approximately $9 \%$ of the variance observed in the test score is attributable to the self-assessment rating of the WHNP when a correlation coefficient defining an accuracy of .30 is applied. If $9 \%$ of the variance is attributed to the self-assessment rating, then $91 \%$ of the test score variation can be accounted for by other factors which may predict knowledge competency in the WHNP group.

Additionally, the study sought to determine if the accuracy of WHNP self-assessment of competency varied across the subgroups of the WHNP specialty. Based on the data, WHNPs were more accurate in self-assessing their knowledge competency related to the subgroup content of Gynecology and Obstetrics than to that of Primary Care. These findings were replicated across all three samples and forms.

\section{Discussion}

Continuing competency of health care professionals must play a significant role in any initiative developed to address quality and patient safety. The issue of accountability for the assurance of professional competency remains an ongoing debate with no clear indication of where the leadership role for implementation lies ${ }^{[9]}$. In a 2008 position statement, the American Nurses Association took the stand that professional competence was a shared responsibility that included individual nurses and the profession as well as professional organizations, accreditation and certification bodies, regulatory agencies, employers and other key stakeholders ${ }^{[10]}$. Over the past several years, organizations and agencies have explored a number of methodologies as potential mechanisms to assess and validate continuing competency within a broad range of health care professions including nursing. In addition to self-assessment, other methodologies proposed or utilized have included clinical hours, mandatory continuing education, use of performance-based development tools, peer review, professional portfolios, interactive computer activities, simulations, and core competency tests. The process of attaining and maintaining certification has also been used as an approach to validate continuing competency ${ }^{[11-15]}$. With a focus on nursing, Whittaker and her colleagues reviewed a number of approaches to continuing competencies as well as the difficult issue of policy development required to address the many aspects of competency validation ${ }^{[16]}$. Of particular interest to the NCC Board was the level of concern expressed in the professional literature and by involved stakeholders in regard to the effectiveness of self-assessment as a mechanism for identifying competency needs of health care professionals. Since self-assessment of learning needs had long formed the basis for educational activities completed in support of NCC's own certification maintenance process, the need to confirm or reject the appropriateness of this approach was recognized. The study as described in this article was undertaken by NCC using random sample groups from NCC-certified Women's Health Care Nurse Practitioners (WHNP), one of six core nursing specialties with active certification examinations offered by NCC in its role as a nationally accredited certification organization. The rationale for undertaking the study was to provide data for discussion and decision-making in regard to continued use of constituent self-assessment of continuing education needs as the basis for the NCC certification maintenance process. The key question was whether or not NCC-certified nurses could adequately self-assess their strengths and weaknesses in regard to the knowledge competencies aligned with their specialty. A review of the literature revealed that attempts to answer this critical question have been the subject of studies and conjecture for several decades ${ }^{[17-21]}$. In 2006, Davis and his colleagues published the results of a systematic database review of 725 articles that addressed the issue of physician selfassessment. Their goal was to determine how accurately physicians were able to self-assess their needs compared with external observation of their competence. Their systematic review, which had a goal similar to the major focus of the NCC pilot project, found that of the 17 studies meeting all of their selection criteria, weak or no association was found when the physicians' self-rated assessments were compared to external assessments. Their overall conclusion was that despite limitations in quality, the preponderance of evidence supported a limited ability on the part of physicians to accurately self-assess and the recommendation was made that consideration should be given to the use of external assessment mechanisms to evaluate competence ${ }^{[17]}$. 
For the research questions posed in this article, the findings demonstrated that the WHNP study population had fairly low ratings. Again if a correlation coefficient of .300 (9\% explained variance) described earlier is applied as a rule of thumb for substantive significance, only 3 of the 36 accuracy indices met this criterion. Although the correlation coefficients obtained in the study were reasonable, they were not considered high enough to omit empirical assessment of knowledge using testing approaches that directly examine knowledge competencies for the specialty. Supportive of this psychometric recommendation from the NCC study were the summary findings within a review paper published by Eva and Regehr who describe a "conundrum" created by the literature on self-assessment. Their conclusions suggested that the improper use of self-assessment is the major flaw and that despite evidence of flawed methodologies in how the effectiveness of selfassessment was evaluated; evidence persisted to indicate that self-assessment is not an effective option for professional self-regulation. In their opinion, the identification of gaps in learning and attention to those gaps would best be met by a model that included external evaluations ${ }^{[20]}$.

The 100 item test developed by NCC for use in the pilot study was reflective of content distribution in the active WHNP core certification examination. The concept of a test instrument as an evaluation tool provided the basis for later development of the specialty assessments administered as an external evaluation instrument to direct maintenance of certification on an individualized basis. In a similar approach, Wendt and Alexander of the National Council State Boards of Nursing (NCSBN) performed a descriptive study based on a non-experimental survey tool designed to collect nursing practice data that could potentially be applied toward the development of a continuing competency assessment instrument for measuring knowledge, skills and abilities of the post entry-level practitioner ${ }^{[22]}$.

Based on concerns raised nationally and with the results of its own empirical evaluation as described in this article, the NCC Board of Directors voted to move forward with a Continuing Competency Initiative that transitioned the certification maintenance process for all six of its active core nursing certification examinations. Under this Initiative, a secure specialty assessment tool reflective of active certification examination content and distribution is used to evaluate individual constituent specialty knowledge competencies at the beginning of each maintenance cycle. Each constituent's specialty assessment results, which have no pass/fail status, are used to develop an individualized learning plan. The learning plan defines the number of contact hours and the core competency content areas to be covered in continuing education activities used for maintenance of a NCC credential. The initial phase that provided orientation to the process and to the individualized learning plan began in 2010 and transitioned to the binding phase beginning with 2014 maintenance cycle deadlines.

In the words of Dame Mary Douglas, renowned social anthropologist, "If you want to change the culture, you will have to start by changing the organization" ${ }^{[23]}$. Supported by the findings of the empirical evaluation presented, the National Certification Corporation has initiated the organizational changes needed to support sustainable life-long learning for the NCC-certified population through a certification maintenance process based on third party validation of specialty knowledge competencies.

\section{Acknowledgement}

We would like to acknowledge the significant contribution of George Engelhart, Jr., Ph.D. of Emory University for his work in the analysis and interpretation of data collected in the course of this study.

\section{References}

[1] Institute of Medicine, Consensus Report. Crossing the Quality Chasm: A New Health System for the 21st Century. 2001. http://iom.edu/Reports/2001/Crossing-the-Quality-Chasm-A-New-Health-System-for-the-21st-Century.aspx.

[2] Institute of Medicine, Workshop Report. Health Professions Education: A Bridge to Quality. 2003. http://iom.edu/Reports/2003/Health-Professions-Education-A-Bridge-to-Quality.aspx. 
[3] Maintaining and Improving Health Professional Competence: the Citizen Advocacy Center Road Map to Continuing Competency Assurance. 2004: 1-16. http://www.nbcrnacpc.com/resources/Documents/4\%20MaintainingImprovingCompetence\%202004.pdf.

[4] National Council of State Boards of Nursing. 2005. Meeting the Ongoing Challenge of Continued Competence. https://www.ncsbn.org/Continued_Comp_Paper_TestingServices.pdf.

[5] Pew Health Professions Commission. Critical Challenges: Revitalizing the Health Professions for the Twenty-First century. 1995. http://www.soundrock.com/sop/pdf/Reforming\%20Health\%20Care\%20Workforce\%20Regulation.pdf.

[6] Swankin D, LeBuhn RA, Morrison R. Implementing Continuing Competency Requirements for Health Care Practitioners. AARP 2006. http://assets.aarp.org/rgcenter/health/2006_16_competency.pdf.

[7] Institute of Medicine, Consensus Report. To Err is Human. 1999. http://iom.edu/Reports/1999/To-Err-is-Human-Building-A-Safer-Health-System.aspx.

[8] http://www.jointcommission.org/about_us/about_the_joint_commission_main.aspx (19 June 2012 date last accessed).

[9] Burns B. Continuing competency-what's ahead? J Perinat Neonat Nurs. 2009; 23: 218-227. PMid:19704289

[10] http://nursingworld.org/MainMenuCategories/Policy-Advocacy/Positions-and-Resolutions/ANAPositionStatements/Position-Sta tements-Alphabetically/Professional-Role-Competence.html (20 June 2012 date last accessed)

[11] Byrne M, Delarose T, King, CA, Leske J, Sapnas KG, Schroeter, K. Continued professional competence and portfolios. Journal of Trauma Nursing. 2007; 14: 24-31. PMid:17420648

[12] Epstein RM, Hundert EM. Defining and assessing professional competence. JAMA. 2002; 28: 7226-7235.

[13] http://allnurses.com/nursing-educators-faculty/performance-based-development-393490.html (14 June 2012, date last accessed).

[14] Lysaght RM, Altschuld JW. Beyond initial certification: the assessment and maintenance of competency in professions. Evaluation and Program Planning. 2000; 23: 95-104. http://dx.doi.org/10.1016/S0149-7189(99)00043-9

[15] Phillipsen NC, Lamm NH, Reier SL. Continuing competency for nursing licensure. J Nurs Pract. 2007; 3: 41-45. http://dx.doi.org/10.1016/j.nurpra.2006.11.005

[16] Whittaker S, Carson W, Smolenski M. Assuring continued competence-policy questions and approaches: how should the profession respond? OJIN 2000.

http://www.nursingworld.org/MainMenuCategories/ANAMarketplace/ANAPeriodicals/OJIN/TableofContents/Volume52000/N o3Sept00/ArticlePreviousTopic/ContinuedCompetence.html.

[17] Davis DA, Mazmanian PE, Fordis M, Van Harrison R, Thorpe KE, Math M et al. Accuracy of physician self-assessment compared with observed measures of competence. JAMA. 2006; 296:1094-1102.PMid:16954489 http://dx.doi.org/10.1001/jama.296.9.1094

[18] Dunning D, Heath C, Suls, JM. Flawed self-assessment: implications for health, education and the workplace. PSPI. 2004; 5: 69-106.

[19] Eva Kw, Cunnington JP, Reiter HI, Keane DR, Norman, GR. How can I know what I don't know? poorself assessment in a well-defined domain. Adv Health SciEduc Theory Pract. 2004; 9: 211-224. PMid:15316272

http://dx.doi.org/10.1023/B:AHSE.0000038209.65714.d4

[20] Eva KW, Regehr G, Self-assessment in the health professions: a reformulation and research agenda. Acad Med. 2005; 80: S46-S54. PMid:16199457 http://dx.doi.org/10.1097/00001888-200510001-00015

[21] Ward M, Gruppen L, Regehr G. Measuring self-assessment: current state of the art. Adv Health SciEduc Theory Pract. 2002; 7: 63-80. PMid:11912336 http://dx.doi.org/10.1023/A:1014585522084

[22] Wendt A, Alexander, M. Toward a standardized and evidence-based continued competence assessment for registered nurses. JONA's Healthcare Law, Ethics and Regulation. 2007; 9: 74-86. PMid:17728575

http://dx.doi.org/10.1097/01.NHL.0000287969.44053.e0

[23] http://www.brainyquote.com/quotes/quotes/m/marydougla237176.html (23 June 2012, date last accessed). 